Article

\title{
Geophysical and Social Influences on Evacuation Decision-Making: The Case of Hurricane Irma
}

\author{
Robin L. Ersing ${ }^{1, *}$, Christianne Pearce ${ }^{2}$, Jennifer Collins ${ }^{2} \mathbb{(}$, Michelle E. Saunders ${ }^{2}$ and \\ Amy Polen ${ }^{3}$ (i) \\ 1 School of Public Affairs, University of South Florida, Tampa, FL 33620, USA \\ 2 School of Geosciences, University of South Florida, Tampa, FL 33620, USA; cjordon@mail.usf.edu (C.P.); \\ collinsjm@usf.edu (J.C.); msaunders1@mail.usf.edu (M.E.S.) \\ 3 College of Public Health, University of South Florida, Tampa, FL 33620, USA; amypolen@usf.edu \\ * Correspondence: rersing@usf.edu
}

Received: 6 July 2020; Accepted: 7 August 2020; Published: 12 August 2020

\begin{abstract}
Understanding the factors that influence evacuation decision-making among local residents is of critical importance to those involved in monitoring and managing weather-related hazards. This study examined both geophysical and social variables that we believe influenced individual decision-making on whether to stay home, seek out a public shelter, or leave the area entirely during Hurricane Irma. A 23-item survey was administered to a convenience sample of adults $(\mathrm{n}=234)$ who resided within a coastal Florida county that received an evacuation warning during Hurricane Irma in 2017. Results suggested sources of information relied on through media, government, family, and social networks contributed to differences in evacuation behavior. Moreover, potential exposure to weather-related conditions, such as flooding and strong winds, along with the likelihood to use available social resources, also influenced decisions to stay or leave the threatened area. Finally, prior evacuation behavior was significantly associated with the decision to evacuate during Hurricane Irma. The decision to evacuate for Hurricane Irma was shown to impact decision-making to evacuate for major hurricanes in the future. If these findings are applied to future storms, a broader conclusion can be made that residents in vulnerable areas may be more likely to evacuate for major hurricanes than they were in the past. Improved understanding of evacuation decision-making can assist emergency managers in preparation and planning to reduce casualties resulting from a hurricane or other weather-related hazard.
\end{abstract}

Keywords: Hurricane Irma; evacuation decisions; geophysical vulnerability; social vulnerability

\section{Introduction}

Evacuations for major natural disasters, like hurricanes, have been of interest to researchers for many years. One of the goals of the research for evacuations is to better understand why people decide to evacuate or stay in the path of danger. What impacts people's decisions to stay or go: social connections, lack of resources to leave, the unreliability of the media to portray the actual threat, or the mindset that "that will never happen to our area"? The decision to stay or go could mean a decision between life and death for many residents in vulnerable areas. Hurricane Irma, in September 2017, provided some insight into the evacuation decisions of Florida's citizens. Since 2005, when Hurricane Katrina devastated the Gulf Coast regions of Louisiana and Mississippi, evacuation behavior and evacuation decision-making have received notable attention in the natural hazards literature $[1,2]$. The high death toll in New Orleans alone was a sobering reminder of what individuals face when making decisions. Although authorities may issue a mandatory order to evacuate, it is ultimately a personal decision with life-threatening consequences to leave or stay. Although a number of factors 
may influence evacuation behavior, two are of particular interest in this study: geophysical conditions of the hazard and social vulnerabilities that restrict access to resources.

In this study, the focus on geophysical and social elements in relation to evacuation decision-making stems from the vulnerability literature that examines both the threat of hazard conditions and the mitigation of social supports. The known Pressure and Release model (PAR) developed by Wisner et al. identifies various social and geophysical pressures believed to heighten the level of susceptibility for individuals and communities, thereby contributing to a disaster [3]. Indeed, conceptualized at an individual-level, these pressures or vulnerabilities shift attention to the role social supports play in buffering people, processes, and places when confronted with actual or perceived deleterious geophysical characteristics of a natural hazard. Although one's evacuation behavior, that is, the decision whether to stay or to go in the advent of a natural disaster, can be based on a myriad of conditions. Our interest here is to better understand if the decision to shelter in place or choose to evacuate is influenced by individual-level perceptions of both geophysical and social factors. According to the Access model developed by Wisner et al., geophysical conditions such as the intensity of a hazard event can place the most socially vulnerable groups at far greater risk for recovery [3]. The Access model posits that social susceptibility may be minimized through access to enhanced resources. To this point, when faced with a mandatory evacuation order due to the threatening characteristics of a hurricane, how might one's assessment of social vulnerabilities, including access to support networks and resources, affect their decision to evacuate?

\section{Background}

Natural hazards vary in their impact on a geographic community depending on the scope of the event including the speed of onset, intensity, and duration. The term vulnerability is often used to conceptualize the potential threat of risk posed by a natural hazard [4,5]. Wisner et al. define disaster vulnerability as the "characteristics of a person or group and their situation that influence their capacity to anticipate, cope with, resist and recover from the impact of a natural hazard" [3] (p. 11). The United Nations International Strategy for Disaster Reduction [UNISDR] suggests that the threat of disaster risk increases within a community when social, economic, and environmental systems are weak and therefore susceptible to the impact of a natural hazard [6]. Although the factors which increase a locality's threat to a hazard may be difficult to quantify, the literature has often addressed the concepts of geophysical and social vulnerability. Geophysical features can be more defined as the risk to an area while social systems characterize the vulnerability to an area [7]. Vulnerability can lead to devastation, particularly if an area has multiple challenges.

As stated previously, this study examines evacuation behavior within the context of geophysical and social vulnerability assessed at the level of the individual. Since 2005 and Hurricane Katrina, a growing body of literature points to a paradigm shift toward the importance of understanding individual perceptions as informing one's construction of disaster risk and the decision to evacuate [8-10]. As Kusenbach and Christmann posit, "... vulnerability is rooted in the knowledge and interpretations (and thus the potential for change) that people have regarding their own and others' placement in the natural and social world" [11] (p. 63). Further evidence is reported in a systematic review of 68 studies from 15 databases that examined resilience and social vulnerability within the context of geophysical conditions of a natural hazard [12]. An important recommendation was the need to further study whether social vulnerability is better viewed within the function of the specific hazard rather than as a property of larger social systems. We believe this has merit for exploring individual-level perceptions of both geophysical and social factors as influencing evacuation decision-making.

\subsection{Geophysical Vulnerability}

Geophysical vulnerability can be determined by the number and type of physical hazards an area is exposed to. These hazards might include events such as fires, earthquakes, lightning, tornadoes, and hurricanes. Tobin and Montz created a list which categorized the components of hazards 
that contribute to geophysical vulnerability [13]. Those components included physical mechanism (e.g., magnitude, duration, and spatial extent); temporal distribution (e.g., frequency, seasonal patterns); spatial distribution (e.g., geographic location); and countdown interval (e.g., preparation time, speed of onset). Geophysical vulnerability also includes how properties can be damaged or destroyed. During a hurricane, damage can be caused by strong winds, flooding due to storm surge or rain, tornadoes, debris falling, the list goes on. Areas with mobile homes, especially those in flood zones, are at a high risk to be destroyed not only by high winds, but also storm surge. Senkbeil et al. examined individual perceptions of geophysical vulnerability during a hurricane evacuation [9]. Respondents at Interstate rest stops along an evacuation route were asked to rank their level of concern about how much damage they believed their homes might sustain. They were also asked about their perceptions of wind speed and the potential damage that might occur. Results showed that most people have misperceptions about wind speeds, even though this geophysical factor of a hurricane is of great concern.

\subsection{Social Vulnerability}

Much of the social vulnerability literature in the realm of natural hazards has been conceptualized using community or systems-level indicators and attributes of individuals. With regard to the latter, disparities relevant to age, gender, race, and culture are often viewed as key socio-demographic variables that influence susceptibility and exposure to risk during an extreme event [14]. For example, Cutter, Boruff, and Shirley identified key categories of social vulnerability including personal wealth, age, race, ethnicity, and occupation. However, they also included several contextual-level variables of social vulnerability such as density of built environment, housing stock and tenancy, and infrastructure dependence [15]. Many of these factors comprise the foundation for the Social Vulnerability Index (SoVI), a tool used to identify communities that may need resources in preparing for hazards or recovering from disasters [15].

Zhang discussed the idea of social vulnerability as the characteristics of a community that can influence their ability to prepare, resist, and then recover from the impacts of a hazard [16]. Unlike the SoVI [15] which explored a variety of contributing factors, Zhang initially viewed social vulnerability as a dichotomous construct including human vulnerability and the ability to access resources [16]. Cutter and Emrich discussed the idea that social vulnerability is not distributed evenly among social groups or different local areas [17]. This suggests that a single standard approach to handling emergency preparedness, response, and recovery may not be the most effective strategy for a given community. In their study, Cutter and Emrich compared different parishes in Louisiana impacted by flooding during Hurricane Katrina [17]. Using the SoVI, they were able to see the many differences between parishes and their ability to respond and recover after a major natural hazard. The primary factors of social vulnerability in these particular parishes were race, gender, and class.

We build on the construct of social vulnerability as defined through the perspective of social connections. How social connections are utilized to influence hazard evacuation behavior remains a critical component for the development of disaster resilience models as part of mitigation and preparedness planning $[18,19]$. Dynes asserts that "social networks provide the channels whereby individuals develop a perception of risk and can be motivated to take some type of preventative action" [19] (p. 18). While social supports are intuitively thought to play a pivotal role in disaster preparedness and decision-making, a paucity of studies on the topic provides mixed results with regard to hazard evacuations [19-21]. Therefore, it remains uncertain just how informal supports and social connections are used to arrive at a decision to leave or stay and whether the process varies in relation to certain social and economic characteristics of individuals and their communities [22].

Miller acknowledges the important role of diverse formal and informal social connections in sharing information and establishing trust during evacuations stemming from Hurricanes Katrina and Rita [23]. Both the number of contacts and the range of contacts across different social roles aided in the evacuation process. Indeed, the density or closeness of social connections and ties with individuals who share similar social and economic characteristics has been shown to provide increased sources 
of support during a natural hazard $[24,25]$. Social isolation stemming from a lack of connectedness with social supports was found to contribute to one's vulnerability, as suggested by the demographic profile of those who did not evacuate during Hurricane Katrina [26]. Likewise, research examining the relationship between social connections and vulnerability to a natural hazard suggests that these networks can work to buffer or reduce the deleterious effects of a disaster and aid in decision-making behavior both pre- and post-disaster [27].

\subsection{Evacuation Behavior}

Evacuation behavior and the decision-making process used by individuals remain a vital topic in the natural hazards literature. It is often difficult for social researchers to study personal behavior at the actual time of an evacuation order. According to Baker and Lindell et al., evacuees are often found to change their plans as time progresses during a major hazard event [28-30]. Another obstacle to studying evacuation behavior can occur due to memory decay which can limit the accuracy of the data collected post-event [31]. As time increases after an evacuation, individuals may have a harder time recalling details such as decision-making and the order of specific actions that occurred during the process. An early study by Baker documented the results of surveys conducted after hurricanes that took place from 1961 to 1989 in locations spanning from the coasts of Texas to the coasts of Maine [29]. The objective was to better understand individual evacuation behavior. A goal of the study was an attempt to create a generic model that could be used to predict evacuation behavior for any given hazardous event including hurricanes. Baker's research found that individual reactions to an evacuation are difficult to precisely measure. However, the information gathered from three decades of hurricane evacuations did show several common trends including factors such as risk area, types of housing, storm threat information, previous hurricane experience, length of residence in hurricane prone areas, and unnecessary evacuations in the past. It was noted that demographic factors of race and gender did not play a significant role in the decision to evacuate. Prior research has conflicted results on the effects of demographic factors such as race and gender on one's protective action decisions such as evacuation [32,33]. Research by Sherman-Morris which focused on the response of a Tornado warning system on a university campus, showed that females were more likely to take shelter during such an event [33]. The more recent study by Miran looked to determine the factors that influenced people to take protective action during a tornado event in 2013 in the Oklahoma City area. Of the factors considered, gender did not play a significant role [32].

More recently, Lazo et al. analyzed people's decisions to evacuate based on two information conditions: viewing a hurricane forecast versus receiving an evacuation order [34]. Residents from two coastal areas, Miami-Dade, Florida, and Houston-Galveston, Texas, were surveyed. Choosing two different areas prone to hurricane impact added more information about how factors affecting evacuation decisions can vary across areas. Analysis of the study included several factors that could influence decisions such as cultural worldviews, past experiences, and risk perceptions. Results from the study suggested people who evacuated due to having viewed a hurricane forecast were more self-motivated and less likely to mention the need to protect family or pets. In contrast, those receiving an evacuation order reported following that order to protect family members including pets. This study is important because it demonstrates that protective actions can influence evacuation decisions. In addition, the study revealed some differences between the two states, indicating differences in culture, experience, and vulnerabilities also play a role in evacuation decision-making. Lazo et al. discuss the importance of having clearly developed evacuation plans to avoid misperceptions about risk and vulnerability.

To further understand how perceptions of risk might affect evacuation behavior, Demuth et al. studied the past experiences of individuals who encountered a hurricane, and how those experiences could influence future decision-making on evacuation [35]. As mentioned previously, past experiences can shape the way a person understands risks, and thus how they will respond to future risks. Demuth et al. collected data from individuals in the Miami-Dade area of Florida to examine past 
hurricane experiences and related property or financial loss, emotional impact, and overall severity of all impacts resulting from the disaster. It is notable that results indicated subjects having reported emotional impacts from the hazard despite not having experienced tangible losses such as damage to property. However, evacuees who did in fact incur property damage (tangible losses) said they were less likely to evacuate the next time because they believed they could better protect their property. This circumstance suggests past evacuations may actually deter people from future evacuations. Overall, the study does point to the importance of understanding the more intangible emotional experiences people have in the midst of a hazard which may factor into decision-making and evacuation behavior.

Another key factor in understanding evacuation decision-making is timing. During Hurricane Ike in 2008, more than 100,000 residents along the Gulf Coast of Texas refused to evacuate when urged. The most common reason people gave for not leaving the area was the concern of getting stuck in traffic backups and delays which was reminiscent of the roadway issues that occurred three years prior during Hurricane Rita [36]. Sadly, when the $22 \mathrm{ft}$. storm surge from Ike made landfall and inundated much of the coast, close to 2000 people had to be rescued from the flooding [37]. Storm surge and flooding of this magnitude hinders emergency crews from responding to the affected area, thus relying on other methods such as boats or helicopters to rescue stranded residents who stayed behind. Certainly, this approach requires more time and resources. Devastation to this degree continues to pose serious obstacles to emergency crews trying to conduct rescue efforts. Seventy-four deaths in Texas were attributed to Hurricane Ike, as well as more than 100,000 homes being flooded and hundreds of thousands individuals left homeless after the destruction of many towns located along the coast [38].

How individuals access, interpret, and use weather information such as hurricane forecasts and warnings can also influence evacuation behavior. Morss and Hayden studied how people obtain, interpret, and use weather forecasts and warnings to inform their decision to evacuate [39]. Texas residents interviewed several weeks after the impact of Hurricane Ike in 2008 reported they believed the Saffir-Simpson scale did an inadequate job conveying the risk and potential for damage caused by a category 2 storm, which included heavy flooding from storm surge in coastal areas. Based on perceptions of the hurricane scale, many residents decided to remain in their homes rather than adhere to a mandatory evacuation order. As a result, people tended to prepare their homes from strong winds, but did not take similar precautions against flooding, which proved to be the more destructive force.

The sources one obtains information from during a disaster play a significant role in evacuation decision-making, shown in the protective action decision model or PADM [40]. The method in which hazard information is conveyed through warnings and graphics can also affect how individuals perceive data to inform their decision to evacuate. It has been observed that the type of graphic presented to an individual can influence their protective action decisions and that different methods of information portrayal with natural hazards can alter an individual's risk perception [41-44]. For example, the study by Ash tested the response to three different tornado warning designs [41]. Three different tornado warning graphics were used in the study to determine how University students would react. Though the graphics all represented the same threat, the student's responses showed they perceived the threat differently for each of the three graphics. This demonstrates that different warning graphics have different responses no matter the threat. Research into dynamic and other graphics has also shown that the use of probabilistic hazard information included within graphics can enhance the effectiveness of the warning $[45,46]$. Specifically with hurricanes, there has been research conducted to address graphical changes to popularly used communication tools such as the cone of uncertainty [44].

Technology, particularly social media, has become another valuable tool in analyzing how people react to and use information to make decisions in hazardous situations. The role of social media in communicating risk is an emerging area of research that holds importance for emergency management to better understand how hazards are publicly conceptualized and communicated, and any impact this might have on evacuation decision-making. Twitter posts from Rockaway, New York, captured before, during, and after Hurricane Sandy in 2012 revealed the extent to which people relied on the 
social media platform to understand, interpret, and share storm information [47]. Though social media can be used to quickly convey important information to a large mass of people, there is also a risk of spreading false or inaccurate information which may result in unnecessary panic. An example of false information sharing was found by Snyder when social media was used to suggest Hurricane Irma in 2017 would make landfall as a category 6 storm [48]. The Saffir-Simpson Hurricane Wind scale does not extend beyond a category 5 rating. This scenario illustrates the importance of ensuring correct and factual weather forecasting information is shared publicly to avoid poor decision-making when confronted with natural hazard.

Studies by Collins et al. also provide further understanding into the factors that influence people's decisions about evacuation $[49,50]$. Two studies of evacuees and non-evacuees impacted by Hurricanes Matthew in 2016 and Irma in 2017 examined how social connections affect evacuation behavior. Social connections were measured across three dimensions: dependability, density, and diversity. Respondent data from Hurricane Matthew revealed the perceived dependability of social connections significantly impacted the decision to evacuate. Specifically, those who did not evacuate believed they had more dependable social relationships leaving them to feel more comfortable staying within the local community. In other words, those not evacuating felt they could rely on their networks of people to aid them if necessary. The density (number of social ties) and diversity (variety of social relationships) of social connections did not significantly influence evacuation behavior. In contrast, respondent data from Hurricane Irma in 2017 suggested the density and diversity of one's social connections played a significant role in the decision to evacuate. Dependability of the relationships had no influence. To explain the difference in findings between the two studies, Collins et al. considered varying attributes of each storm, including the position of the cone of uncertainty in weather forecasts, the timing of the storms with Irma making impact very soon after the devastation of Hurricane Harvey, and the overall perceived difference between the meteorological conditions of Matthew and Irma.

\section{Problem Statement}

The continued loss of life, serious injury, and destruction of property resulting from the impact of natural hazards warrants additional studies on evacuation behavior, particularly factors that result in people choosing to remain in the path of a storm. Indeed, empirical evidence from the study of evacuation decision-making is of critical importance to those involved in monitoring and managing weather-related hazards. This study examined both geophysical and social variables that we believe influence individual decision-making on whether to stay home, seek out a public shelter, or leave an area entirely during Hurricane Irma. In 2017, Irma made landfall as a category 3 storm in Southwest Florida and traveled up the western coast heading toward Pinellas County and the Tampa Bay area of Hillsborough County. As the hurricane approached, Florida's residents made final preparations for a storm that had been described as "historical" and "devastating". Stores were depleted of food and supplies such as bottled water, batteries, plywood, and tarps; gas stations were running low on fuel; and interstates were swamped with motorists from both coasts making a last-minute retreat out of the state. An estimated 6.5 million residents of Florida were under mandatory or voluntary evacuation orders, making it one of the largest evacuations ever ordered in the United States [51]. Residents in Pinellas County, an area vulnerable to storm surge, were anxiously watching the path of Hurricane Irma. Storm surge, which is the abnormal rise of sea water associated with a tropical cyclone, has been shown to devastate low lying coastal areas, and is considered one of the most dangerous impacts of a hurricane. This area of Florida had not received a direct hit by a major hurricane since 1921.

\section{Study Area}

Pinellas County, Florida, served as the site for this study. The county is on a peninsula surrounded by the waters of the Gulf of Mexico and Tampa Bay, making this area critically vulnerable to storm surge and flooding. Pinellas County is a popular tourist destination due to the miles of white sandy beaches, countless water activities, and a multitude of beach front hotels. It is also a popular area for retirees 
from the northern states to settle down and escape the snow. Pinellas County is demographically diverse with areas of concentrated poverty adjacent to areas of extreme affluence. Mobile home parks are as prevalent as multi-million dollar mansions. Pinellas County has many areas just at or barely above sea level, making most of the county vulnerable to storm surge associated with a hurricane. With a population of nearly one million, the county ranks sixth as most populous in Florida, [52].

Two days before Hurricane Irma was forecast to make landfall, a mandatory evacuation was issued as the county prepared for the possibility of a 15-foot storm surge. Although more than 354,000 residents were impacted by the order to evacuate, not all heeded the warning. Despite warnings of human casualties and destruction of property, a portion of residents chose to stay in place and ride out the storm at their own homes. Just over 24,000 residents left the immediate area at risk and stayed in one of 17 shelters opened to the public in Pinellas County [53]. Fortunately, the residents of Pinellas County were spared from the worst of the storm as its track shifted eastward to the center of the state. The county did however receive tropical storm force winds and category 1 hurricane-strength gusts. Storm surge was also negligible.

\section{Data and Methods}

The purpose of this study was to explore factors that influence evacuation decision-making. Both geophysical and social variables that we believe influence individual decision-making were examined to understand individual evacuation behavior including whether to stay home, seek out a public shelter, or leave the area entirely during Hurricane Irma. Specifically, we were interested in knowing the following: (1) Does access to various sources of information influence evacuation decision-making?; (2) Does potential exposure to geophysical conditions influence evacuation decision-making?; (3) Do social connections influence evacuation decision-making?; and (4) Does prior evacuation behavior influence current evacuation decision-making? In order to facilitate comprehension of the results, these questions are found in Table 1 (see Section 4.3) and are referenced throughout the Results section.

\subsection{Instrument}

Data were collected using a hurricane evacuation decision-making and risk perception survey developed for this study. The survey was comprised of 23-items, constructed with closed-end and Likert scale responses. Survey items covered several dimensions. Actual evacuation behavior was recorded as whether the respondent obeyed or ignored the government-issued evacuation order for Hurricane Irma. We asked if the respondent remained at home or in the local area of impact (i.e., non-evacuation), or sought shelter (public or private) outside the evacuation zone (i.e., evacuation), and how long after the order was announced was the decision made. Previous evacuation experience was considered affirmative if the respondent ever vacated an area under threat of a hurricane between the years 2004 and 2016. Future evacuation decision-making was assessed by asking whether they would choose to evacuate for a future hurricane. Respondents were then asked to select the factors that would influence their future actions to evacuate or not if a major hurricane was forecasted to impact the immediate area. Factors to consider included transportation, family members, pets, health/disability, risk of damage to home, risk of looting, finances, risk of flooding or wind damage, loss of power, personal safety, or some other factor. Reliance on information sources was measured with a five-point Likert scale ranging from "not relied on at all" to "relied on the most". Respondents were asked to rate how much various sources of information on Hurricane Irma influenced their decision to evacuate during Hurricane Irma. Sources included national, local, electronic, and print media; radio; government officials; social networks; or some other source they could identify. Geophysical factors resulting from Hurricane Irma were measured with a five-point Likert scale ranging from "did not influence at all" to "influenced the most". Respondents were asked to rate how their perceptions of the impact from wind, rain, flooding, and storm surge influenced their decision to evacuate. Respondents were also asked if they knew the level of evacuation zone they lived in, what a hurricane evacuation 
order meant in terms of hours before impact of the storm, and if they knew if the evacuation order for Hurricane Irma as mandatory or voluntary. Social factors were measured in terms of personal social connections using nine items that were a sub-scale excerpted from a larger instrument designed to assess perceptions of individual social networks [54]. Each item was scored on a Likert scale of 1-4 with 1 representing "Strongly disagree" and 4 representing "Strongly agree". The first dimension of the scale contained four items to represent integration of different types of relationships in one's network (i.e., Integration), while the remaining five items represented the dimension of expectation and propensity to mobilize social resources (i.e., Mobilization). The sub-scale was scored in accordance with the original instrument by tallying Likert responses for each dimension [54]. A total score of 12 or higher on the first dimension (Integration), suggested having more diverse social connections in one's life, while a total score of 15 or higher on the second dimension (Mobilization), suggested having greater ability to put those social resources into action.

\subsection{Sample}

The sampling strategy for this study had several criteria to achieve our goal of understanding actual evacuation behavior. First, we referred to the Pinellas County Social Vulnerability Index prepared by the Centers for Disease Control and Prevention (CDC, 2016), along with 2010 census tract data [52,55]. Geographic Information System (GIS) analysis aided identifying areas in the county with the presence of both geophysical and social vulnerabilities (see Figure 1). Four categories of variables were considered including socio-economic indicators, housing composition, race and ethnicity, and transportation. These variables were chosen based on their importance in considering risk of threat from a natural hazard. We then intersected areas with higher rates of social vulnerability with county designated evacuation zones to account for geophysical vulnerability. Areas found to be both social and geophysical vulnerable became the sample recruitment locations for the study. Within each targeted location, convenience sampling was used to gather participants $(n=234)$. In accordance with Institutional Review Board (IRB) approval, study participants had to be 18 years of age or older, a resident of Pinellas County, and had to have lived in the county during the time of Hurricane Irma in 2017. Demographics of the sample $(n=234)$ show $71 \%$ of participants were white and $67.7 \%$ female. The mean age of respondents was 45 years old. Overall, $40.5 \%$ of respondents had a college degree and $46.4 \%$ of households reported annual incomes of less than $\$ 40,000$ per year.

As mentioned, the survey was distributed in three separate locations due to their proximity to evacuation zones (see Figure 2). We believe this may have helped to increase the response rate. Each of the public areas was known to have abundant foot traffic and was situated within major community shopping centers. Surveys were administered over two days using three teams of graduate and undergraduate students from the University of South Florida. The survey took approximately $10 \mathrm{~min}$ to complete, and to avoid concerns with literacy, each survey was read aloud to the participant who then indicated which response to mark. Although surveys were being administered nine months post-disaster, many residents who lived through the experience of Hurricane Irma were very eager to share their stories and experiences. 


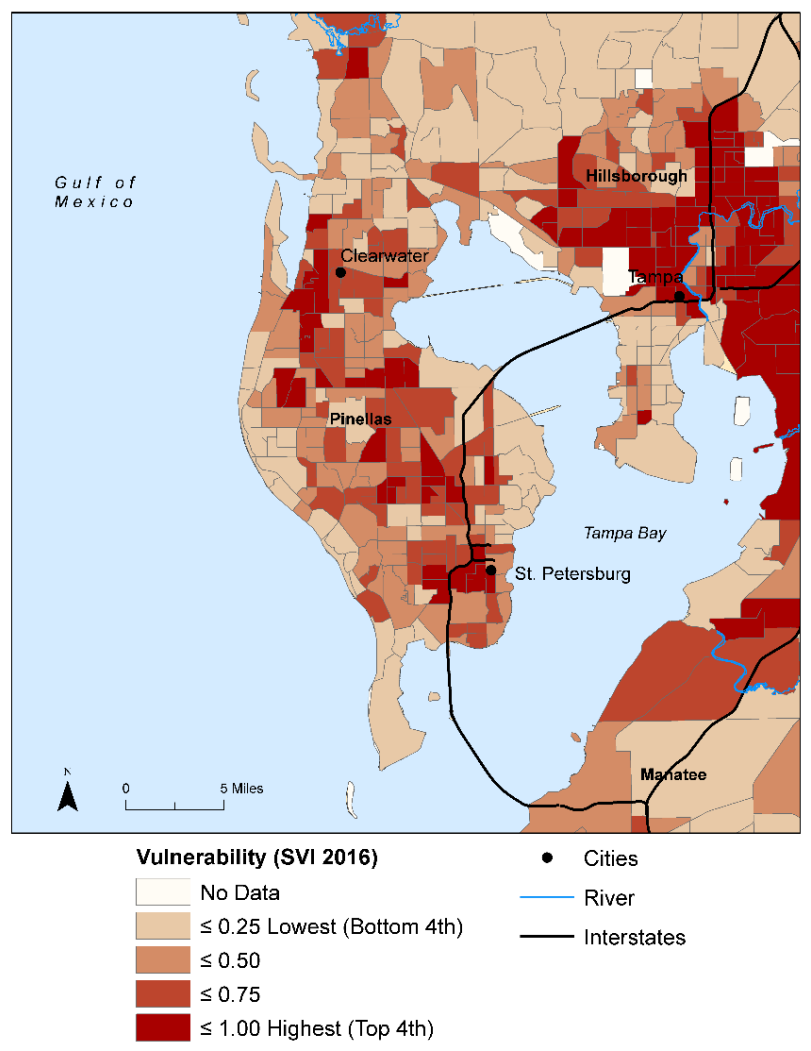

Figure 1. Geophysical and social vulnerability in Pinellas County.
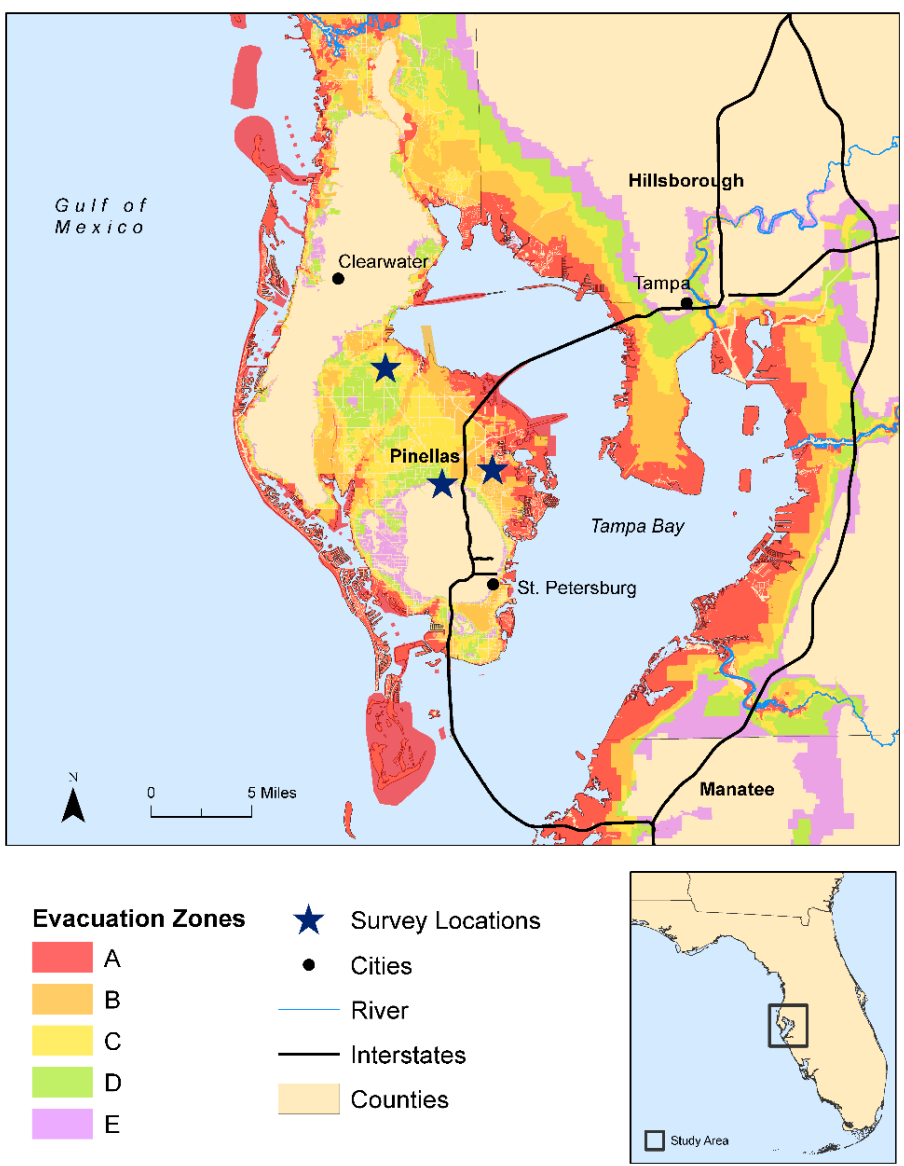

Figure 2. Survey distribution locations. 


\subsection{Statistical Analysis}

As mentioned previously, this study focused on four research questions (see Table 1). Results of the data analysis to address these questions follow. Survey items used in each analysis are found in the Supplementary Materials.

Table 1. List of research questions used in this study.

\begin{tabular}{c} 
Questions \\
\hline Q1. Does access to various sources of information influence evacuation decision-making? \\
Q2. Does potential exposure to geophysical conditions influence evacuation decision-making? \\
Q3. Do social connections influence evacuation decision-making? \\
Q4. Does prior evacuation behavior influence current evacuation decision-making? \\
\hline
\end{tabular}

Initially, respondents were grouped by their actual evacuation behavior during Hurricane Irma resulting in three groupings: Stay-at-Home (those who did not evacuate and stayed in place), Shelter (those who evacuated to a shelter outside of the evacuation zone), and Leave (those who evacuated the area). For some statistical procedures, the latter two groups (Shelter and Leave) were combined to create the Evacuation group. This permitted analysis to more closely focus on differences between those who chose to remain at home during the hazard (Stay-at-Home group) and those who chose to leave the hazard area (Evacuation group).

Answers to Q1 in Table 1 were based on participant responses to survey item 9 (see Supplementary Materials). This item was used to analyze sources of information people rely on to help make a decision to stay or leave during a hurricane. Respondents rated different sources of information, such as national media and government officials, on a Likert scale from 0-4 indicating no reliance to most relied on. Mann-Whitney U tests were conducted to compare mean ranks between the Stay-at-Home group and the Evacuation group with regard to reliance on information sources.

A Mann-Whitney test was also used to analyze answers to Q2 in Table 1. Responses to survey item 19 to determine how each of the geophysical conditions associated with a hurricane could influence the decision to evacuate or not. This was also done by employing a Likert scale from $0-4$ with 0 representing no influence and 4 representing most influence. The Mann-Whitney $U$ test compared mean rank differences between the Stay-at-Home group and the Evacuation group.

Answers to Q3 in Table 1 were based on participant responses to survey item 18, which addressed social factors that could potentially affect evacuation decisions. Scores from this section of the instrument were divided into two dimensions. The first dimension contained four items to represent integration of different types of relationships in the network (i.e., Integration), while the remaining five items represented the dimension of expectation and propensity to mobilize social resources (i.e., Mobilization). As discussed previously (see Section 4.1), a score of 12 or higher on the first dimension (Integration) suggests having more diverse social connections in one's life, while a score of 15 or higher on the second dimension (Mobilization) suggests having greater ability to put those social resources into action. Pearson Chi-Square tests of independence were performed to compare Integration and Mobilization against the binary evacuation status, and a Spearman's rho was used to compare the Integration and Mobilization measures against evacuation status, education, and household income.

Analysis was also conducted to understand the respondent's actual and intended behavior for past, current, and future evacuation decision-making. Answers to Q4 in Table 1 came from multiple survey items. Participant responses to survey item 3, Hurricane Irma evacuation decisions, were divided into those who stayed (Stay-at-Home group) and those who left (Evacuation group), and were compared to the responses given for survey item 4, previous hurricane evacuation decisions, which were dichotomous (yes/no). A McNemar test was performed to identify the proportion of respondents who changed their evacuation for Irma compared to previous hurricanes. Responses to survey item 21, future evacuation intentions, were binary (yes/no). A Chi-square test was used here 
to determine the individual's likelihood to evacuate or not in future scenarios based on their Irma evacuation behavior.

\section{Results}

Once collected, surveys $(n=234)$ were coded and entered into a database for analysis using the statistical software program SPSS (IBM, New York, USA, version 25). Descriptive tabulations are presented along with statistical tests to look for significant relationships in the data.

\subsection{Reliance on Information}

Respondents were asked about hurricane information sources they relied on in order to make their decision to stay at home or evacuate during Hurricane Irma. They were asked to rate 12 different sources of information ranging from national and local media on television, radio, government officials, and people in their lives such as family and friends and neighbors. Likert scaling was used with 0 being "Not at all relied on" and 4 being "Most relied on". In general, respondents had the highest reliance on local media, with a mean score of 3.36 compared to their reliance on print media with the lowest mean score of 0.50 . Mann-Whitney $U$ analysis was also conducted using a binary evacuation status, comparing those who stayed and those who evacuated. Reliance on Radio Broadcasts $(U=5323.5$, $p=0.037)$, government officials $(\mathrm{U}=4937, p=0.003)$, family more than 50 miles away $(\mathrm{U}=5103$, $p=0.005)$, and social networks $(\mathrm{U}=5363, p=0.046)$ were all found to be significant with respondents who evacuated having a higher mean ranking than those who stayed (see Table 2).

Table 2. Mann-Whitney U results comparing the Stay-at-Home group to the Evacuation group during Hurricane Irma with information sources for radio, government, family, and social networks as significant.

\begin{tabular}{cccc}
\hline \multicolumn{4}{c}{ Information Sources Relied on during Hurricane Irma } \\
\hline Information Sources & Mann-Whitney U & $\mathbf{Z}$ & $\boldsymbol{p}$ \\
\hline National Media & 5782.500 & -1.358 & 0.175 \\
Local Media & 6166.500 & -0.589 & 0.556 \\
Electronic Media & 5618.500 & -1.637 & 0.102 \\
Print Media & 6134.000 & -0.620 & 0.535 \\
Radio Broadcasts & 5323.500 & -2.089 & $\mathbf{0 . 0 3 7}$ \\
Government Officials & 4937.000 & -2.980 & $\mathbf{0 . 0 0 3}$ \\
Family Nearby You & 5976.500 & -0.676 & 0.499 \\
Family Far Away & 5103.000 & -2.801 & $\mathbf{0 . 0 0 5}$ \\
Neighbors & 6214.000 & -0.229 & 0.819 \\
Friends Nearby You & 5860.000 & -1.052 & 0.293 \\
Friends Far Away & 5916.000 & -0.974 & 0.330 \\
Social Networking & 5363.000 & -1.996 & $\mathbf{0 . 0 4 6}$ \\
\hline
\end{tabular}

\subsection{Geophysical Factors}

Respondents were asked a series of questions on geophysical hazards associated with a hurricane that could potentially affect their decision to evacuate. They were asked to rate how much each hazard influenced their decision to evacuate or not for Hurricane Irma on a Likert scale with 0 representing "Not influenced me at all" and 4 representing "Most influenced me". A comparison was made between the binary evacuation status of respondents who stayed and those who evacuated using a Mann-Whitney $U$ test of differences. Results revealed storm surge $(U=4913, p=0.003)$, strong winds $(\mathrm{U}=4778.5, p=0.001)$, flooding from rain $(\mathrm{U}=5063, p=0.007)$, size of the storm $(\mathrm{U}=4454, p \leq 0.001)$, and tornadoes $(\mathrm{U}=5262, p=0.040)$ all showed as a significant influence on the respondents' decision to evacuate (see Table 3). 
Table 3. Mann-Whitney U test results comparing the Stay-at-Home group to the Evacuation group during Hurricane Irma for geophysical hazards with surge, winds, storm size, and tornado threat as significant.

\begin{tabular}{cccc}
\hline \multicolumn{4}{c}{ Hurricane Irma Evacuation Decision's Based on Geophysical Hazards } \\
\hline Geophysical Hazard & Mann-Whitney U & $\mathbf{Z}$ & $\boldsymbol{p}$ \\
\hline Storm Surge Flooding & 4913 & -3.023 & $\mathbf{0 . 0 0 3}$ \\
Strong Winds & 4778.5 & -3.285 & $\mathbf{0 . 0 0 1}$ \\
Flooding from Rainfall & 5063.5 & -2.686 & $\mathbf{0 . 0 0 7}$ \\
Size of Storm & 4454.5 & -4.042 & $\mathbf{0 . 0 0 0}$ \\
Tornadoes & 5262 & -2.050 & $\mathbf{0 . 0 4 0}$ \\
Social Factors & 6135.5 & -0.387 & 0.699 \\
\hline
\end{tabular}

\subsection{Social Factors}

Results for social factors were assessed through nine questions that explored social connections with family and friends. Scores were analyzed along two dimensions: Integration of different types of relationships in one's social network (i.e., diversity of relationships), and Mobilization to mobilize social resources (i.e., utility of relationships). As discussed previously, respondents were asked to rate each question on a scale of 1-4 with 1 representing "Strongly disagree" and 4 representing "Strongly agree". As explained previously, to calculate a respondent's diversity of social connections (i.e., Integration), a tallied score of 12 or higher from designated questions was classified as having a high integration of different types of relationships in their social network. Similarly, to calculate utility of relationships (i.e., Mobilization), a tallied score of 15 or higher from respective questions was classified as having high mobilization. Pearson Chi-Square tests of independence were performed to compare integration and mobilization against the binary evacuation status (those who Evacuated and those who Stayed-at-Home). Integration and the binary evacuation status showed a significant relationship $\left(X^{2}(1, \mathrm{n}=203)=4.072, p=0.044\right)$. Those who stayed home had a higher percentage of respondents with low integration compared to those who left the area. In other words, those who stayed behind during Hurricane Irma did not have as much diversity in their relationships. Mobilization was not shown to be significant.

Using a Spearman's Rho test, correlation was examined for integration and mobilization against annual household income and the respondents' highest education completed. This test indicated a moderate positive significant relationship between integration and annual income $\left(r_{s}=0.192, p=0.005\right)$ as well as a moderate negative relationship between mobilization and highest education completed $\left(\mathrm{r}_{\mathrm{s}}=-0.191, p=0.005\right)$. This suggests those in the sample with higher income are likely to have more diverse relationships, whereas those with a higher education are more likely to mobilize and activate their social connections.

\subsection{Actual Evacuation Behavior}

The majority of those surveyed (62\%) indicated that they stayed at home during Hurricane Irma, while $27 \%$ evacuated the area, and $11 \%$ went to a shelter outside of any evacuation zone. This means, $62 \%$ of the sample $(\mathrm{n}=145)$ were "Irma non-evacuees" compared to $38 \%$ who were "Irma evacuees" $(\mathrm{n}=89)$.

\subsection{Previous Evacuation Behavior}

When asked about past evacuation behavior from 2004 to 2016, this sample $(n=232)$ revealed about one in five $(21 \%)$ had ever done so. Instead, respondents overwhelmingly reported $(79 \%)$ having had no previous experience evacuating for a hurricane. Not surprisingly, of those never having evacuated $(\mathrm{n}=184)$, two-thirds $(66 \%)$ stated they stayed home during Hurricane Irma. In contrast, among those people that did have evacuation experience, there was an even split (50\%) between those who decided to leave for Hurricane Irma and those who chose to stay behind. Most importantly is a 
focus on shifting behavior or how many people changed from one decision to another. Results show that $27 \%$ of respondents who had not previously evacuated for a hurricane did evacuate for Irma, while only $10 \%$ of respondents who had previously evacuated for a hurricane decided not to evacuate for Irma. Results from McNemar's test found a significant difference with a $p \leq 0.001$ (see Table 4).

\subsection{Future Evacuation Decision-Making}

The decision of whether to evacuate or not for a future hurricane was found to be significantly influenced based on the respondents' experience with Hurricane Irma. Among 230 respondents, $62 \%(n=145)$ indicated they would evacuate should another major hurricane threaten the area where they reside. Results from a chi-square test $\left(X^{2}(1)=16.63, p<0.001\right)$ showed a significant association between having evacuated for Hurricane Irma and wanting to evacuate in the future. Respondents reported that their decision to evacuate in the future was influenced by four factors: concern for safety $(26 \%)$, fear of a power outage $(23 \%)$, wind damage $(23 \%)$, and flooding $(21 \%)$. In comparison, just over one-third of the sample (36\%) said they would not evacuate for a future storm and shared the reasons that influenced their decision. The top four factors reflected personal issues including pets (20\%), fear of looting $(15 \%)$, care of family members $(14 \%)$, and finances (14\%). Additional factors that affected the decision to not leave their home for a future hurricane were transportation issues (13\%), dealing with damage to house $(12 \%)$, and having a disabled member in the household $(6 \%)$.

Table 4. Chi-square results between respondents' previous hurricane evacuation decisions compared to their evacuation decision for Hurricane Irma.

\begin{tabular}{|c|c|c|c|c|}
\hline \multicolumn{2}{|c|}{$\begin{array}{l}\text { Previous Hurricane Evacuation Decisions Compared } \\
\text { to Hurricane Irma Evacuation Decision }\end{array}$} & \multicolumn{3}{|c|}{$\mathrm{X}^{2}=4.035, p=0.045$ McNemar's $p<0.001$} \\
\hline \multirow{2}{*}{\multicolumn{2}{|c|}{ Previous Hurricane Evacuation Decisions }} & \multicolumn{3}{|c|}{ Hurricane Irma Evacuation Decision } \\
\hline & & No & Yes & Total \\
\hline \multirow{3}{*}{ No } & Count & 121 & 63 & 184 \\
\hline & \% within Prev. Hurricane Evacuation & $65.8 \%$ & $34.2 \%$ & $100.0 \%$ \\
\hline & \% within Hurricane Irma Evacuation & $83.4 \%$ & $72.4 \%$ & $79.3 \%$ \\
\hline \multirow{3}{*}{ Yes } & Count & 24 & 24 & 48 \\
\hline & $\%$ within Prev. Hurricane Evacuation & $50.0 \%$ & $50.0 \%$ & $100.0 \%$ \\
\hline & \% within Hurricane Irma Evacuation & $16.6 \%$ & $27.6 \%$ & $20.7 \%$ \\
\hline \multirow{3}{*}{ Total } & Count & 145 & 87 & 232 \\
\hline & \% within Prev. Hurricane Evacuation & $62.5 \%$ & $37.5 \%$ & $100.0 \%$ \\
\hline & \% within Hurricane Irma Evacuation & $100.0 \%$ & $100.0 \%$ & $100.0 \%$ \\
\hline
\end{tabular}

\section{Discussion}

Our attempt to understand the decision of whether to stay or go when faced with an impending hurricane remains a complex conundrum consistent with past studies in this area $[29,34,56]$. Despite millions of Floridians leaving their residences to seek safer shelter away from the path of Hurricane Irma, it seems study participants never having evacuated in at least the preceding decade remained consistent in their behavior. Indeed, even among those who had previous evacuation experience, half chose to remain at home for Irma. The latter finding is alarming as some individuals may believe they are capable to protect their property from the geophysical forces of the storm and from social threats such as looting if they shelter in place. However, the more concerning challenge for emergency managers is to convince those who have never evacuated to do so. This challenge is similar to what was found during Hurricane Sandy when fewer than $30 \%$ of residents chose to evacuate despite warnings of the imminent threat to safety [57]. Some of this may be attributed to a communication overload or even what may sound like mixed messages from weather forecasting and statements from local and state government leaders. This is consistent with recent studies that have found the influence of evacuation messaging on the decision of whether or not to shelter in 
place [58,59]. Images of traffic jams, shelters being referred to as places of last resort, and the fear that once evacuated you may not be able to return home as soon as the storm passes due to hazards from debris all cause concern for those who may have considered evacuating.

In contrast, the significant association between experiences from Hurricane Irma and the decision to evacuate in the future if faced with a similar storm is reassuring. Concern over geophysical impacts was a key influencer to evacuate next time. Fear over loss of power, destruction from wind, and the threat of flooding were found to be of most importance in the decision to seek safer shelter away from an impending hurricane. However, social factors remained a mitigating reason among one-third of participants to remain home during the next storm. Clearly, concerns over caring for family members and pets are known to influence evacuation decision-making as we learned from Hurricane Katrina in 2005 [60]. Since then, county and local-level emergency management organizations have done much to establish pet friendly shelters and safe havens for those who are disabled or require special medical attention. Despite these efforts, it seems some individuals may still find it difficult to evacuate.

Information sources relied on during a severe weather threat can influence perceptions of the event as well as one's behavioral response. Among 12 choices, local media sources were found to be relied on most for information on a hurricane with print media relied on the least. It is not surprising that people would turn to local information outlets to track what is happening in their community as a major storm approaches. Likewise, radio broadcasts and information from government officials being significant sources to those evacuating is expected since these individuals may be in transit to find safe shelter. The importance of social connections is also noted as a significant influence on deciding to evacuate with the reliance on family outside the area (more than 50 miles away), and personal social networks being most relied on by evacuees. This suggests possible reliance on resources in the form of news or offers of assistance that might come through social supports as part of the evacuation process.

In terms of geophysical influences on evacuation decision-making, significance was found with five hazard indicators including storm surge, strong winds, flooding from rain, size of the storm, and the possibility of tornadoes. It is noteworthy that participants responded according to their perceptions of these storm conditions which may be further influenced by the timing of when they received information on the size and strength of the hurricane. Certainly, if a storm is intensifying as it approaches an area, it may be too late to physically evacuate, leaving a family to hunker down and ride it out. Similarly, weather forecasters frequently remind viewers about the "cone of uncertainty" and the need to pay close attention to subtle but important shifts in speed, direction, and strength. An individual's distance to the coast or proximity to low-lying areas or bodies of water may also influence the decision to evacuate due to specific hazards such as storm surge or flooding from rainfall. Distance was not a factor we were able to account for but something that could be assessed in a future study. We do not know how all this information may factor into one's evacuation decision-making.

As mentioned previously, social connections were shown to have an influence on the decision of whether or not to evacuate. The significance of diversity (integration) of relationships in one's social network was found to influence evacuation behavior. In other words, those who chose to shelter at home (non-evacuees) had less diverse social connections. This suggests that a variety of relationship types may provide access to varied resources which could aid in an evacuation. Previous research suggests that the lack of social ties with people outside an evacuation zone may result in non-evacuation as the person may not have another place to shelter [61]. The positive relationship between integration of social connections and annual income leads us to believe that with increased income comes a greater likelihood to form more diverse friendships and other types of relationships. Similarly, the significant relationship found between mobilization of social connections and education suggests an increased opportunity to activate those relationships in a time of need. Finally, these findings support the literature on social capital $[27,50]$ as an intangible experience that in the midst of a hazard may factor into decision-making and evacuation behavior.

A limitation of this study is that our survey sampling site locations were within areas with high geophysical and social vulnerability, and while respondents' home locations (indicated by zip 
code) were throughout Pinellas County, low vulnerability areas were not compared. We suggest future research include spatial analyses in order to address this limitation. Another limitation for this study is that only survey items were used within our analyses. We suggest future research to consider advanced analysis to control for other factors that might affect the dependent variable of evacuation decision-making.

\section{Conclusions}

In September 2017, Hurricane Irma struck Florida as a major category 4 storm leaving behind 84 fatalities and over $\$ 50$ billion in damages, making it one of the costliest storms to impact the state. Despite Irma becoming one of the largest evacuation events in U.S. history, not everyone heeded the warning to leave. This study found support that both geophysical and social factors have an influence on evacuation behavior and evacuation decision-making. Specifically, we examined whether access to information sources, exposure to weather conditions, social connections, and previous evacuation experience influenced evacuation decision-making and actual behavior during Irma. Our results suggest that both storm-related factors and social connections play a part in this process. Concerns about wind damage, flooding, and loss of power were significant indicators for those wanting to seek safety away from the hurricane. More personal considerations such as caring for family members, pets, and finances appear to become constraints to evacuation. With this in mind, it is noteworthy that evacuees said they relied on their social networks and family living outside the evacuation zone as part of their decision to leave or stay.

This study also added knowledge to the understanding of why some people may decide not to follow an evacuation order, further supporting prior research results within the field of disaster sociology $[9,49,50]$. First, among those with prior evacuation experience, half chose to stay home and shelter in place during Irma. In 2017, Florida experienced a busy season with two tropical storms and two hurricanes affecting the state prior to Irma [62]. However, none of these weather events directly impacted our study site, Pinellas County. This leads us to speculate if perhaps a "crying wolf" situation may have occurred with residents reassuring themselves that Irma would not pose a direct threat $[29,63]$. Second, among those who have never evacuated for a hurricane, $66 \%$ also decided not to leave for Irma. Given the strength of this hurricane, we wonder if such a large number of non-evacuees may need to be looked at from two perspectives. In other words, was the decision to stay a personal choice, or were there constraining factors that made it more difficult or even impossible to evacuate [2]? With Hurricane Katrina, demographic factors were found to pose a barrier for evacuation, particularly race and income [64]. In our study, we found those who were more affluent in terms of income and education were more likely to have more diverse social networks and were more likely to use those social connections.

This study also indicated that in the future if another major hurricane were to impact the area, $62 \%$ would decide to evacuate even if they had not evacuated for Hurricane Irma. If the same study was performed in other vulnerable areas to tropical systems and produced similar results, this would indicate that populations are becoming more aware of the importance of evacuating. There have been many well-publicized storms in recent years: Hurricane Harvey (2017), Hurricane Irma (2017), Hurricane Maria (2017), and Hurricane Michael (2018), just to name a few. The damage and destruction of such strong storms could help influence people to be better prepared for future storms and have an evacuation plan of their own if they find themselves in the path of a hurricane. In the future, this could save the lives of people who are being threatened by a major storm. However, there is some evidence to suggest that the intent to evacuate does not guarantee the decision to evacuate for a future tropical cyclone and instead may be more connected with previous evacuation behavior, storm strength, or when ordered to evacuate $[35,65]$.

Future research into human behavior and the decision-making process on whether or not to evacuate from a natural hazard merits continued attention in the literature. We believe understanding the geophysical, social, and additional factors that influence evacuation behavior can help public 
administrators and emergency managers better prepare communities to reduce serious injury and loss of life. Continued research on understanding the role of social connections, and the related resources that they provide, may help people to predetermine where they will shelter outside an evacuation zone. Similarly, studies looking at other constraining factors may aid the field of emergency management in developing tools and supports that would remove such obstacles and promote safe evacuation behavior. We also believe it is important to study tools that can be used by the public to better understand weather forecasts. Likewise, studies to understand which information sources are preferred and the types of information to communicate may aid in the decision-making process and influence evacuation behavior. As knowledge continues to build from an array of disciplinary perspectives, evidence-based policies and practices can be developed to better support community preparedness.

Supplementary Materials: Hurricane Evacuation Decision Making and Risk Perception Survey is available online at http://www.mdpi.com/2073-4433/11/8/851/s1.

Author Contributions: Conceptualization, C.P., J.C., and R.L.E.; methodology, C.P.; formal analysis, M.E.S., A.P., R.L.E., and J.C.; investigation, C.P.; writing—original draft preparation, R.L.E.; writing-review and editing, J.C., C.P., A.P., and M.E.S. All authors have read and agreed to the published version of the manuscript.

Funding: This research received no external funding.

Acknowledgments: This article benefitted greatly from the insights of anonymous reviewers. The authors wish to thank the students of the Weather, Climate, and Society Research Experience for Undergraduates for their assistance and support with this study.

Conflicts of Interest: The authors declare no conflict of interest.

\section{References}

1. Adeola, F.O. Katrina Cataclysm: Does Duration of Residency and Prior Experience Affect Impacts, Evacuation, and Adaptation Behavior Among Survivors? Environ. Behav. 2009, 41, 459-489. [CrossRef]

2. Thiede, B.C.; Brown, D.I. Hurricane Katrina: Who Stayed and Why? Popul. Res. Policy Rev. 2013, 32, 803-824. [CrossRef]

3. Wisner, B.; Blaikie, P.; Cannon, T.; Davis, I. At Risk: Natural Hazards, People's Vulnerability and Disasters, 2nd ed.; Routledge: Abingdon-on-Thames, UK, 2003.

4. Paton, D.; Johnston, D. Disasters and communities: Vulnerability, resilience and preparedness. Disaster Prev. Manag. 2001, 10, 270-277. [CrossRef]

5. Zakour, M.; Gillespie, D.F. Community Disaster Vulnerability: Theory, Research, and Practice; Springer: New York, NY, USA, 2013.

6. United Nations International Strategy for Disaster Reduction. UNISDR Strategic Framework. Available online: https://www.unisdr.org/we/inform/publications/51557 (accessed on 12 August 2020).

7. Chakraborty, J.; Tobin, G.; Montz, B. Population Evacuation: Assessing Spatial Variability in Geophysical Risk and Social Vulnerability to Natural Hazards. Nat. Hazards Rev. 2005, 6, 23-33. [CrossRef]

8. Kusenbach, M.; Simms, J.L.; Tobin, G.A. Disaster vulnerability and evacuation readiness: Coastal mobile home residents in Florida. Nat. Hazards 2010, 52, 79-95. [CrossRef]

9. Senkbeil, J.; Collins, J.; Reed, J. Evacuee Perception of Geophysical Hazards for Hurricane Irma. Weather Clim. Soc. 2018, 11, 217-227. [CrossRef]

10. Widener, M.J.; Horner, M.W.; Metclaf, S.S. Simulating the effects of social networks on a population's hurricane evacuation participation. J. Geogr. Syst. 2013, 15, 193-209. [CrossRef]

11. Kusenbach, M.; Christmann, G. Understanding Hurricane Vulnerability: Lessons from Mobile Home Communities. In Disaster Resiliency: Interdisciplinary Perspectives; Kapcu, N., Hawkins, F., Rivera, F.I., Eds.; Taylor \& Francis: New York, NY, USA, 2013; pp. 61-83.

12. Ran, J.; MacGillivray, B.H.; Gong, Y.; Hales, T.C. The application of frameworks for measuring social vulnerability and resilience to geophysical hazards within developing countries: A systematic review and narrative synthesis. Sci. Total Environ. 2020, 711, 134486. [CrossRef]

13. Tobin, G.A.; Montz, B.E. Natural Hazards: Explanation and Integration, 2nd ed.; Guilford: New York, NY, USA, 1997.

14. Morrow, B.H. Identifying and mapping community vulnerability. Disasters 1999, 23, 1-18. [CrossRef] 
15. Cutter, S.L.; Boruff, B.J.; Shirley, W.L. Social Vulnerability to Environmental Hazards. Soc. Sci. Q. 2003, 84, 242-261. [CrossRef]

16. Zhang, N.; Huang, H. Social Vulnerability for Public Safety: A Case Study for Beijing, China. Chin. Sci. Bull. 2013, 58, 2387-2394. [CrossRef]

17. Cutter, S.L.; Emrich, C.T. Moral Hazard, Social Catastrophe: The Changing Face of Vulnerability along the Hurricane Coasts. Ann. AAPSS 2006, 604, 102-112. [CrossRef]

18. Buckle, P. 2006: Assessing social resilience. In Disaster Resilience: An Integrated Approach; Paton, D., Johnston, D., Eds.; Charles C. Thomas: Springfield, IL, USA, 2006; pp. 88-104.

19. Dynes, R.R. The importance of social capital in disaster response. Univ. Del. Disaster Res. Cent. Prelim. Paper 2002, 327, 59.

20. Mathbor, G.M. Enhancement of community preparedness for natural disasters: The role of social work in building social capital for sustainable disaster relief and management. Int. J. Soc. Work 2007, 50, 357-369. [CrossRef]

21. Riad, J.K.; Norris, F.H. Hurricane threat and evacuation intentions: An analysis of risk perception, preparedness, social influence, and resources. Univ. Del. Disaster Res. Cent. Prelim. Paper 1998, 271, 34.

22. Moore, S.; Daniel, M.; Linnan, L.; Campbell, M.; Benedict, S.; Meier, A. After Hurricane Floyd passed: Investigating the social determinants of disaster preparedness and recovery. Fam. Community Health 2004, 27, 204-217. [CrossRef]

23. Miller, L.M. Collective disaster responses to Katrina and Rita: Exploring therapeutic community, social capital, and social control. South. Rural Sociol. 2007, 22, 45-63.

24. Haines, V.; Beggs, J.J.; Hurlbert, J.S. Exploring the structural contexts of the support process: Social networks, social statuses, social support, and psychological distress. In Social Networks and Health; Levy, J.A., Pescosolido, B.A., Eds.; Advances in Medical Sociology Series, Vol. 8; Emerald Group Publishing Limited: Bingley, UK, 2002; pp. 269-292.

25. Haines, V.; Hurlbert, J.S. Network range and health. J. Health Soc. Behav. 1992, 33, 254-266. [CrossRef]

26. Brinkley, D. The Great Deluge: Hurricane Katrina, New Orleans, and the Mississippi Gulf Coast; Morrow: New York, NY, USA, 2006; p. 716.

27. Hawkins, R.L.; Maurer, K. Bonding, Bridging and Linking: How Social Capital Operated in New Orleans following Hurricane Katrina. Br. J. Soc. Work 2010, 40, 1777-1793. [CrossRef]

28. Baker, E. Predicting response to hurricane warnings. Mass Emergencies 1979, 4, 9-24.

29. Baker, E. Hurricane Evacuation Behavior. Int. J. Mass Emergencies Disasters 1991, 9, 287-310.

30. Lindell, M.K.; Lu, C.J.; Prater, C.S. Household decision making and evacuation in response to hurricane Lili. Nat. Hazards Rev. 2005, 6, 171-179. [CrossRef]

31. Stallings, R.A. Methods of Disaster Research; Xlibris: Bloomington, IN, USA, 2002.

32. Miran, S.M.; Ling, C.; Rothfusz, L. Factors influencing people's decision-making during three consecutive tornado events. Int. J. Disaster Risk Reduct. 2018, 28, 150-157. [CrossRef]

33. Sherman-Morris, K. Tornado warning dissemination and response at a university campus. Nat. Hazards 2010, 52, 623-638. [CrossRef]

34. Lazo, J.K.; Bostrom, A.; Morss, R.E.; Demuth, J.L.; Lazrus, H. Factors Affecting Hurricane Evacuation Intentions. Risk Anal. 2015, 25, 1837-1857. [CrossRef]

35. Demuth, J.L.; Morss, R.E.; Lazo, J.K. The Effects of Past Hurricane Experiences on Evacuation Intentions through Risk Perceptions and Efficacy Beliefs: A Mediation Analysis. Weather Clim. Soc. 2015, 8, 327-344. [CrossRef]

36. Hurricane Evacuations: Why Some Won't Go. Available online: https://www.livescience.com/15762hurricane-evacuations-won.html (accessed on 12 August 2020).

37. Arrillaga, P.; Root, J.; Shannon, K.; Simpson, D.; Castro, A.; Williams, M.; Coe, A. Hurricane Ike Spurs 2000 Rescues, Thousands More Await; Associate Press: New York, NY, USA, 2008.

38. Zane, D. Tracking Deaths Related to Hurricane Ike, Texas. Disaster Med. Public Health Prep. 2008, 5, $23-28$. [CrossRef]

39. Morss, R.E.; Hayden, M.H. Storm Surge and "Certain Death": Interviews with Texas Coastal Residents following Hurricane Ike. Weather Clim. Soc. 2010, 2, 174-189. [CrossRef] 
40. Lindell, M.; Perry, R. The protective action decision model: Theoretical modifications and additional evidence. Risk Anal. 2012, 32, 616-632. [CrossRef]

41. Ash, K.D.; Schumann, R.L., III; Bowser, G.C. Tornado warning trade-offs: Evaluating choices for visually communicating risk. Weather Clim. Soc. 2014, 6, 104-118. [CrossRef]

42. Jon, I.; Huang, S.-K.; Lindell, M.K. Perceptions and reactions to tornado warning polygons: Would a gradient polygon be useful? Int. J. Disaster Risk 2018, 30, 132-144. [CrossRef]

43. Jon, I.; Huang, S.-K.; Lindell, M.K. Perceptions and expected immediate reactions to severe storm displays. Risk Anal. 2019, 39, 274-290. [CrossRef] [PubMed]

44. Radford, L.; Senkbeil, J.C.; Rockman, M. Suggestions for alternative tropical cyclone warning graphics in the USA. Disaster Prev. Manag. 2013, 22, 192-209. [CrossRef]

45. Miran, S.M.; Ling, C.; Gerard, A.; Rothfusz, L. The effect of providing probabilistic information about a tornado threat on people's protective action. Nat. Hazards 2018, 94, 743-758. [CrossRef]

46. Miran, S.M.; Ling, C.; James, J.J. People's thresholds of decision-making against a tornado threat using dynamic probabilistic hazard information. Int. J. Disaster Risk Reduct. 2020, 42, 101345. [CrossRef]

47. Morss, R.E.; Demuth, J.L.; Lazrus, H.; Palen, L.; Barton, C.M.; Davis, C.A.; Snyder, C.; Wilhelmi, O.V.; Anderson, K.M.; Ahijevych, D.A.; et al. Hazardous Weather Predication and Communication in the Modern Information Environment. Bull. Am. Meteorol. Soc. 2017, 98, 2653-2674. [CrossRef]

48. Category 6? If Hurricane Irma Becomes the Strongest Hurricane in History, It Could Wipe Entire Cities off the Map. Available online: http://theeconomiccollapseblog.com/archives/category-6-if-hurricane-irma-becomesthe-strongest-hurricane-in-history-it-could-wipe-entire-cities-off-the-map (accessed on 12 August 2020).

49. Collins, J.M.; Ersing, R.; Polen, A. Evacuation Decision-Making during Hurricane Matthew: An Assessment of the Effects of Social Connections. Weather Clim. Soc. 2017, 9, 769-776. [CrossRef]

50. Collins, J.M.; Ersing, R.; Polen, A.; Saunders, M.; Senkbeil, J. The Effects of Social Connections of Evacuation Decision Making during Hurricane Irma. Weather Clim. Soc. 2018, 10, 459-469. [CrossRef]

51. As Irma Shifts West, Powerful Winds Batter Florida Keys. Available online: https://www.npr.org/sections/ thetwo-way/2017/09/09/549704585/-the-storm-is-here-floridians-window-to-evacuate-shrinks-as-irmabears-down (accessed on 12 August 2020).

52. QuickFacts, Pinellas County, FL. Available online: https://www.census.gov/quickfacts/pinellascountyflorida (accessed on 12 August 2020).

53. Pinellas County, Florida Hurricane Irma After-Action Report. Available online: https://www.cna.org/CNA_ files/centers/IPR/cia/HurricaneIrmaReport-013118-final.pdf (accessed on 12 August 2020).

54. Van der Gaag, M.J.; Snijders, T.B. The Resource Generator: Measurement of individual social capital with concrete items. Soc. Netw. 2005, 27, 1-29. [CrossRef]

55. CDC's Social Vulnerability Index 2016. Available online: https://svi.cdc.gov/Documents/CountyMaps/2016/ Florida/Florida2016_Pinellas.pdf (accessed on 12 August 2020).

56. Hasan, S.; Ukkusuri, S.; Gladwin, H.; Murray-Tuite, P. Behavioral model to understand household-level hurricane evacuation decision making. J. Transp. Eng. 2011, 137, 341-348. [CrossRef]

57. The Hurricane Sandy Place Report: Evacuation Decisions, Housing Issues and Sense of Community. Available online: https://academiccommons.columbia.edu/doi/10.7916/D82806TN (accessed on 12 August 2020).

58. Cuite, C.L.; Shwom, R.L.; Hallman, W.K.; Morss, R.E.; Demuth, J.L. Improving Coastal Storm Evacuation Messages. Weather Clim. Soc. 2017, 9, 155-170. [CrossRef]

59. Fairchild, A.; Colgrave, J.; Jones, M.M. The challenge of mandatory evacuation: Providing for and deciding for. Health Aff. 2006, 25, 958-967. [CrossRef]

60. Brackenridge, S.; Zottarelli, L.K.; Rider, E.; Carlsen-Landy, B. Dimensions of the Human-Animal Bond and Evacuation Decisions among Pet Owners during Hurricane Ike. Anthrozoos 2012, 25, 229-238. [CrossRef]

61. Petrolia, D.R.; Bhattacharjee, S. Why Don't Coastal Residents Choose to Evacuate for Hurricanes? Coast. Manag. 2010, 38, 97-112. [CrossRef]

62. National Oceanic and Atmospheric Administration Extremely Active 2017 Atlantic Hurricane Season Finally Ends. Available online: https://www.noaa.gov/media-release/extremely-active-2017-atlantic-hurricaneseason-finally-ends (accessed on 12 August 2020).

63. Dow, K.; Cutter, S.L. Crying wolf: Repeat responses to hurricane evacuation orders. Coast. Manag. 1998, 26, 237-252. [CrossRef] 
64. Allen, T.D. Katrina: Race, Class, and Poverty. J. Black Stud. 2007, 37, 466-468. [CrossRef]

65. Meyer, M.A.; Brant, M.J.; Purdum, C.; Breen, K.; Iles, R.L. Previous Hurricane Evacuation Decisions and Future Evacuation Intentions among Residents of Southeast Louisiana. Int. J. Disaster Risk Reduct. 2018, 31, 1231-1244. [CrossRef] 